\title{
Economia da cultura e impactos ambientais do carnaval em Corumbá, MS
}

\section{Culture economy and environmental impacts of the carnival in Corumbá, MS}

La economía de los cultivos y los impactos ambientales de carnaval en Corumbá, MS

Denise Abrão Nachif ${ }^{1}$ Gilberto Luiz Alves²

${ }^{1}$ Doutoranda do Programa de Meio Ambiente e Desenvolvimento Regional da Universidade Anhanguera-Uniderp, Campo Grande, MS. E-mail: denisenachif@ucdb.br

${ }^{2}$ Professor Doutor do Programa de Meio Ambiente e Desenvolvimento Regional da Universidade Anhanguera-Uniderp, Campo Grande, MS. E-mail: gilbertoalves9@uol.com.br 
Resumo: Este artigo articula as relações entre "economia da cultura" do carnaval em Corumbá, MS, e os impactos que podem ser percebidos no meio ambiente de uma cidade situada num dos maiores santuários ecológicos do mundo, o Pantanal. O foco recai sobre o desafio de conciliar interesses entre a economia da cultura manifesta no evento e os interesses socioambientais impactados pelos resíduos produzidos durante os festejos. Para tanto, conectamos os temas históricos do carnaval, da cultura local e do meio ambiente por meio da revisão de fontes secundárias.

Palavras-chave: carnaval; economia da cultura; meio ambiente.

Abstract: This article articulates the relations between the "culture economy" of the carnival in Corumbá, MS, and the impacts that can be perceived in the environment of a city located in one of the largest ecological sanctuaries in the world, the Pantanal. The focus is on the challenge of reconciling interests between the culture economy manifested in the carnival of Corumbá, MS, and the socio-environmental interests impacted by the waste produced during the celebrations. Therefore, we connect the historical themes of carnival, local culture and the environment by reviewing secondary sources.

Key words: carnival; culture economy; environment.

Resumen: En este trabajo se articula la relación entre el carnaval "economía cultural" en Corumbá, MS, y los impactos que se puede percibir en el ambiente de una ciudad situado en uno de los mayores santuarios ecológicas más importantes del mundo, el Pantanal. La atención se centra en el reto de conciliar los intereses entre la cultura de la economía que se manifiesta en el evento y los intereses sociales y ambientales afectados por los residuos producidos durante las festividades. Para ello, conectamos los temas de carnaval históricos, la cultura local y el medio ambiente a través de la revisión de fuentes secundarias.

Palabras clave: carnaval; economía de la cultura; el medio ambiente. 


\section{INTRODUÇÃO}

Todas as nações possuem características naturais ou culturais que as representam perante outras nações, projetando, interna e externamente, imagens e representações, quer positivas, quer negativas.

Amplamente conhecido pelas praias, pelo clima tropical, pela floresta Amazônica ou pelo bioma Pantanal e respectivas flora e fauna, entre outros traços, o Brasil também ganha notória visibilidade por suas práticas culturais, das quais o carnaval e o futebol são as mais emblemáticas, sendo o primeiro, em especial, marcado também por estereótipos. Um desses é a representação ambígua da mulher brasileira, ora percebida por sua beleza e sensualidade, ora tendo sua imagem deslocada para uma visão mercadológica, que a toma como objeto passível de exploração. O turismo sexual vem a reboque dessa imagem - e esse juízo no contexto do carnaval em Corumbá, Mato Grosso do Sul (MS), não está livre desse dilema.

Embora não seja este o foco deste artigo, esse registro aponta para o risco de que as construções culturais constituam estereótipos que podem ser prejudiciais à imagem de uma nação.

O objeto de análise deste trabalho é o carnaval da cidade Corumbá, MS, e pesquisar esse universo requer ir além do mundo das aparências, pois trata-se de questões sensíveis ao ser humano. O objetivo é refletir sobre como conciliar interesses de expressão cultural de uma sociedade, interesses mercadológicos e interesses socioambientais.

Do ponto de vista da economia da cultura, pondera-se sobre questões ambientais e sustentabilidade, proeminentes na festa carnaval em Corumbá, MS, localizada na região do Pantanal, divisa fronteiriça Brasil-Bolívia. Descreve-se o carnaval corumbaense pelo prisma da economia da cultura, destacando os impactos promovidos pela ação antrópica e a necessidade de um planejamento ambiental 
para festejos populares nacionais.

Importa acentuar o aspecto epistemológico do trabalho, focou-se na concepção da economia da cultura, sociedade corumbaense e suas relações com a festa popular carnaval, bem como preocupações ambientais.

De abordagem qualitativa, essa pesquisa foi mediada pela leitura e análise de documentos impressos e digitais, jornais, livros e artigos.

\section{ECONOMIA DA CULTURA E CULTURA LOCAL}

A sociedade contemporânea desta segunda década do século XXI está fortemente influenciada pelas novas tecnologias digitais da informação e comunicação interligadas em redes telemáticas. Os impactos das apropriações dessas novas tecnologias podem ser sentidos nas dimensões econômica, artística, cultural, educacional e comportamental.

O momento atual assinala a importância da "economia da cultura" como elemento estratégico para o desenvolvimento de qualquer nação. É preciso, no entanto, entender e interpretar o papel da economia da cultura na geração de riquezas, de modo que se possam conciliar aspectos humanísticos, artísticos, culturais, ambientais, entre outros.

A economia da cultura é importante alternativa à promoção da cultura popular distribuída por todos os recantos do país, com suas especificidades ou singularidades, cada vez mais valorizadas no mundo globalizado.

O conceito de economia da cultura utilizado neste artigo procura ir além do conceito de indústria cultural proposto por Adorno e Horkheimer (1997), à medida que se busca, aqui, abarcar atividades como artesanato, turismo cultural, festas e tradições, que trazem em si um valor mais cultural que econômico. São riquezas para os 
indivíduos, para as sociedades, para as nações, garantindo-lhes uma identidade cultural.

Enfim, economia da cultura é uma economia que se sustenta no imaterial e tem impactado as economias do mundo todo. Vejamos, como exemplo, o domínio de produção cinematográfica norte-americano em todo o mundo. Leitão (2007, s/p) aponta que:

Do ponto de vista da economia, a expressão "economia da cultura" identifica o conjunto de atividades econômicas relacionadas à cultura. Do ponto de vista da cultura, trata-se do conjunto de atividades culturais com impacto econômico. Pode-se incluir neste conjunto qualquer prática direta ou indiretamente cultural que gere valor econômico, além do valor cultural. A economia é, portanto, uma das dimensões da cultura. E a "economia da cultura" constitui um campo da economia. A expressão serve para definir este campo.

A partir da análise de Leitão (2007), podemos interpretar o carnaval do ponto de vista da economia e suas consequências para a sociedade como um todo.

No Brasil, o carnaval é uma festa popular tradicional e passou por processos de transformação ao longo de sua história, acompanhando o ritmo das mudanças socioeconômicas e culturais de cada época. Como afirma Canclini (2000), o culto tradicional não é apagado pela industrialização dos bens simbólicos. No carnaval, artesãos e músicos dividem espaços nos barracões das escolas de samba ao levarem para a passarela do samba a marca da criatividade e da cultura local. Afinal, a criatividade é um dos elementos importantes dos festejos carnavalescos, envolvendo música, dança, alegorias, fantasias, abundantes na cultura e na sociedade brasileira, que se transformam em produtos culturais consumidos por milhões de pessoas.

A cientista social Maria Isaura Pereira de Queiroz (1973), quando se refere às festas populares como manifestação da cultura de um povo, menciona que o homem expressa valores sociais de forma 
adaptativa para contar uma história, estabelecendo articulação direta entre o passado e o presente.

A cultura, nesse sentido, sendo um conjunto de práticas provenientes da vida social, tem como função organizar e dar sentido a essas práticas. É, pois, uma produção a serviço das manifestações do homem, estabelecendo-se pela criação cultural e artística, como resultado do aprimoramento de seus valores e em todos os seus aspectos (BARBOSA, 2004 ).

Nesse sentido, vale evocar aqui aspectos da memória da região pesquisada, o Pantanal sul-mato-grossense, que já mereceu uma telenovela de grande sucesso exibida entre 1997 e 1998 pela extinta TV Manchete: a telenovela "Pantanal", esta permitiu que grande parte da população brasileira tomasse conhecimento da região e sua cultura singular.

Durante a transmissão de "Pantanal", pôde-se observar o poder dos meios de comunicação e do "gênero" entretenimento, que atingiu grande número de pessoas, chegando ao ponto de incomodar a emissora líder em audiência no Brasil, a rede Globo.

É certo que as telenovelas são um produto da economia da cultura e, como qualquer produto, não estão isentas de críticas, assim como ocorreu com os filmes na perspectiva do discurso da indústria cultural:

Ultrapassando de longe o teatro de ilusões, o filme não deixa mais à fantasia e ao pensamento dos espectadores nenhuma dimensão na qual estes possam, sem perder o fio, passear e divagar no quadro da obra fílmica permanecendo, no entanto, livres do controle de seus dados exatos, e é assim precisamente que o filme adestra o espectador entregue a ele para se identificar imediatamente com a realidade. Atualmente, a atrofia da imaginação e da espontaneidade do consumidor cultural não precisa ser reduzida a mecanismos psicológicos. Os próprios produtos [...] paralisam essa capacidade em virtude de sua 
própria constituição objetiva. (ADORNO; HORKHEIMER, 1997, p. 119).

O audiovisual, visto pelo viés da indústria cultural - proposta, na década de 1940/50, por Adorno e Horkheimer, pertencentes à chamada Escola de Frankfurt -, apresentava-se como um produto alienante para as camadas populares.

Evidente que não se pretende, neste artigo, desconsiderar as ideias dos autores, mas inferir que mais de cinquenta anos se passaram e, nesse ínterim, novas posições, menos radicais e pessimistas, surgiram. Autores mais recentes, como Lipovetsky e Serroy (2011, p. 7), afirmam: "[...] a era hipermoderna transformou o sentido, a superfície social e a economia da cultura".

Dessa forma, comenta-se sobre o sentido da cultura para a mídia no mundo globalizado, algo negociável, modificado de acordo com as mudanças sociais. Lipovetsky e Serroy (2011, p. 10) cunham o termo "cultura-mundo" para explicar o momento em que vivemos:

Se é preciso falar de cultura-mundo é também porque a sociedade de mercado, ou o hipercapitalismo de consumo que a concretiza, é simultaneamente um capitalismo cultural com crescimento exponencial, o das mídias, do audiovisual, do webmundo. A cultura-mundo designa a era da formidável ampliação do universo da comunicação, da informação, da midiatização.

Nesse cenário, a festa popular carnaval é um produto midiático importante para a economia da cultura brasileira e transcende as fronteiras do próprio país através das mídias impressas, digitais, virtuais e audiovisuais adaptadas à realidade contemporânea.

O carnaval corumbaense reúne as características anunciadas, e conhecer um pouco de sua história nos faz refletir sobre a importância dos temas aqui abordados. 


\section{BREVE HISTÓRIA DE CORUMBÁ, MS}

Cidade mais antiga do estado de Mato Grosso do Sul, fundada em 21 de setembro de 1778 e emancipada em 5 de julho de 1850, Corumbá é uma cidade portuária (Rio Paraguai) que teve seu apogeu no século XIX e posterior declínio em meados do século XX.

A cidade guarda preciosos registros arquitetônicos com seus belos casarões e sobrados em estilo europeu, tombados em 1992 pelo Patrimônio Histórico Nacional, e conta com uma população miscigenada, composta por imigrantes de várias origens, como libaneses, árabes, sírios, italianos, portugueses, entre outros povos, e pelos povos nativos - os índios das línguas Arawak, Guaicuru, Jê, Macro-Jê, Tupi Guarani e Zamuco -, também repletos de histórias e lendas.

E são essas histórias, de imigrantes e de nativos, que abastecem o repertório dos sambas-enredo das escolas de samba do carnaval corumbaense (SOUZA, 1973).

Entre outras características relevantes, Corumbá traz também a marca de polo turístico importante do Brasil, capaz de atrair visitantes do exterior, seja para o turismo da pesca, seja para o ecoturismo, seja para o de viagens culturais. O turismo local gera emprego e renda para a população, compartilhando com a atividade da economia da cultura, em que se inscreve o carnaval.

\section{ASPECTOS HISTÓRICOS, CULTURAIS E AMBIENTAIS DO CARNAVAL}

Como o carnaval não é uma festa popular originária de Corumbá, MS, ou do Brasil, entendemos necessária uma incursão, ainda que breve, pelas raízes dessa manifestação cultural.

A festa popular carnaval, oriunda das celebrações dionisíacas nas ruas de Roma, nos séculos VII e VI a.C., apresentava um carro com grande tonel de vinho, que, distribuído em abundância ao povo, 
causava grandes euforias (BARBOSA, 2004). Desse princípio, a festa prosperou como contraponto a um cotidiano marcado pelo trabalho duro e pela sucessão de proibições e de experiências desagradáveis, entre elas os conflitos hierárquicos.

Desde a experiência dos povos egípcios de festas da colheita até as celebrações cristãs que antecediam às penitências da Quaresma, a festa, desfigurando o real, numa tentativa de satirizar as convenções religiosas, sociais e políticas, apresentava-se como uma festa pagã de adeus à carne (carne-vale), celebrando com fartura as carnes e bebidas, a dança sem limites, o sexo, e o desejo de beleza (ARAúJO, 2003 ).

Empregado com sucesso desde o século XIV, o festejo carnaval assumiu um caráter libertino no Ocidente a partir do século XVIII e, em culturas andinas e pós-coloniais, representa uma evolução das festas religiosas, mantendo em si um composto híbrido cultural (CANCLINI, 2011).

Nessa perspectiva, os padrões de comportamento herdados das festas populares dos ciclos litúrgicos deslocam-se para padrões de consumo durante o festejo, não apenas de comidas e bebidas, mas também de artigos, fruto da revolução industrial, para atender às exigências da nova ordem nas relações de produção (SOUZA, 2004).

No Brasil do início do século XX, com a mudança da corte para o Rio de Janeiro, o festejo popular carnaval foi institucionalizado no modelo europeu, incentivando todo tipo de atividade comercial e artesanal dirigida aos serviços da indústria cultural (QUEIROZ, 1973).

Nos últimos anos, críticas contundentes em relação à produção acirrada para atender as demandas do turismo, têm-se dirigido aos impactos ambientais, especialmente aqueles causados pelos resíduos sólidos, produzidos pelo homem contemporâneo em uma sociedade de consumo de produtos industrializados e descartáveis. Esses resíduos degradam o ambiente e concorrem para a proliferação de mosquitos e rastejantes. Estudos que abordam as festas populares 
nacionais da perspectiva gastronômica têm-nas concebido como empreendimentos turísticos de alto consumo, que produzem descarte considerável exercendo impactos negativos sobre o meio.

Nesse sentido, o turismo pode ser capitaneado pelas classes hegemônicas, difundindo seus valores e seus interesses, que estão "longe da produção verdadeira e real, não fantasiosa, protagonizada pelos atores sociais ao longo da história" (PRUDENTE, 2011, p. 79).

Assim, as festas populares, na condição de categorias culturais, são cadenciadas pelas condições históricas reais, percebidas, sentidas e vividas pelas pessoas, que produzem sentidos e significados. Porém, ao longo do tempo, estimuladas pela produção de renda e como sistemas de comunicação que passam a transmutar ideologias, significados e valores; surgem em espaços físicos com caracteres geográficos condicionados pelos processos históricos através dos quais são colocadas tensões em diferentes frestas (QUEIROZ, 1973).

A exemplo disso, constata-se, nos últimos carnavais do Brasil, o surgimento de vários sambas-enredo calcados em questões socioambientais, trazendo em seu bojo questões culturais ancestrais, fazendo críticas à sociedade contemporânea. Cabe relembrar o famoso samba-enredo de autoria de Joãozinho Trinta, para a escola de samba Beija-flor de Nilópolis, "Ratos e urubus... larguem minha fantasia", apresentado no carnaval carioca de 1989, que trouxe para a passarela do samba uma dura crítica social. Com muita criatividade e ousadia, a escola apresentou uma estética grotesca: um Cristo Redentor vestido em farrapos. Proibido pela Justiça, entrou na passarela do samba envolto em plásticos pretos e com uma faixa de protesto com as palavras "Mesmo proibido, olhai por nós".

Vale mencionar que, assim como outras manifestações culturais, a forma de expressar o carnaval não é a mesma em todo o território brasileiro, em especial os ritmos musicais nos desfiles carnavalescos: nas ruas de Olinda e Recife, prevalece o frevo; na Bahia, o axé, que se 
desenvolve pelas ruas de Salvador com os trios-elétricos, ingressando na indústria de produção cultural baiana; no Rio de Janeiro, o samba, entre outras peculiaridades.

Outro aspecto diz respeito ao ato performático da festa ou aos atores sociais que nela se envolvem: enquanto os carnavais carioca e paulistano (assim como o corumbaense) se materializam em desfiles na avenida ou no sambódromo, a tradição mineira expõe os blocos temáticos, no Piauí, são os carros decorados que ganham espaço no "Corso", e em Pernambuco, o Galo da Madrugada e os antológicos bonecos de Olinda, marcam a sua presença.

Importante também remeter a um fato destacado por Gaudin (2000): no Nordeste, o contexto econômico-turístico favorável dos estados tem, já há mais de duas décadas, concorrido para uma redescoberta da região por turistas nacionais e internacionais, chegando a silenciar estereótipos tradicionais da região - terra de seca e de gente sofrida, entre outros.

Resta acrescentar que, dentre as formas peculiares de intervir no mundo, as festas populares revelam-se como mecanismos concretos do estudo do cotidiano, ressignificando formas de criação, de expressão e de resiliência, dando vazão, enfim, à subjetividade (BAKHTIN, 1987). Assim, articulam-se nessas manifestações os sentidos de cultura e de lazer, em que se produz um "[...] conjunto de modos de fazer, ser, interagir e representar, definindo o modo pelo qual a vida social se desenvolve" (FARIA, 2001).

O problema é que, independentemente do local em que as festas ocorram, elas assumem, além da representação dos aspectos singulares, uma marca identitária de uma cidade, estado, região ou país. Os impactos que sua contraparte econômica ou "industrial" promove ao ambiente, proporcionam o desconforto da população e desvalorização do ambiente. 


\section{O CARNAVAL DE CORUMBÁ E OS IMPACTOS NO AMBIENTE}

O carnaval de Corumbá dos últimos anos segue o padrão do maior carnaval do Brasil, o do Rio de Janeiro, cujo auge está na apresentação das escolas de samba na passarela do samba. No carnaval carioca, apresentado na avenida Marquês de Sapucaí e, no carnaval corumbaense, exposto na avenida General Rondon, as escolas de samba exibem-se em espaço público, porém privatizado para a ocasião. O evento geralmente é televisionado, transformando-se num grande produto da economia da cultura, "exportado" para diversos países.

Inspirado nesse modelo de carnaval com características de um grande show, o carnaval de Corumbá se apresenta na acomodação exclusiva, cercada pelos casarios antigos tombados pelo patrimônio histórico e às margens do Rio Paraguai. É nesse cenário exuberante que o carnaval de Corumbá transcorre, tendo como ponto alto os desfiles das dez escolas de samba, onze blocos oficiais e cordões.

Segundo dados a presentados em reportagem da jornalista Paula Maciulevicius, do site campograndenews.com.br, a estrutura para a realização do carnaval de 2015, com "arquibancada, camarotes e palco",

[...] vem com mais de 120 toneladas de ferro e equipamentos. De sonorização, são 140 mil watts de potência ao longo da passarela e na Praça Generoso Ponce, onde acontecerão os shows populares. Os camarotes ao longo da Avenida General Rondon terão capacidade para comportar 1.040 foliões, além de 400 metros de arquibancadas na Rua Frei Mariano e na General Rondon, com capacidade para quatro mil pessoas.

$[\ldots]$

Devidamente cadastrados na Prefeitura, serão 70 barracas padronizadas que vão oferecer comida e bebida durante a folia e mais 210 ambulantes. Ao longo da avenida também serão colocados 100 banheiros químicos. (MACIULEVICIUS, 2015). 
Como se pode observar nesses dados, há uma logística para que a festa proporcione condições de conforto aos foliões. Nessa mesma reportagem, quando entrevistado, o prefeito comenta: "Em termos econômicos compensa. Ano passado foram cerca de R\$ 12 milhões que circularam entre hotel, alimentação, farmácia, postos de gasolina. É uma coisa importante em termos de crescimento cultural e de economia" (MACIULEVICIUS, 2015).

Outros dados relevantes do carnaval do ano de 2015 em Corumbá aparecem numa outra reportagem, agora do site douradosnews.com.br:

Mais de 155 mil pessoas assistiram aos desfiles de escolas de samba e blocos, na Avenida General Rondon, e participaram dos bailes populares, na Praça Generoso Ponce, durante os cinco dias de carnaval em Corumbá. Na última noite da folia no Pantanal, a Polícia Militar estimou um público de 30 mil pessoas. Foi a maior concentração dos últimos carnavais na cidade. O público recorde (40 mil) foi registrado na segunda-feira, quando desfilaram as três escolas melhor classificadas nos anos anteriores, a Mocidade Independente da Nova Corumbá, a Vila Mamona e a Império do Morro. (s/a, 2015) Podemos inferir que festas populares atraem grande números de pessoas, irrigam a economia local, porém, pontos relevantes como impactos de resíduos no ambiente, parecem ainda pouco considerados nas estratégias de governança pública e privada. (CARNAVAL..., 2005).

O até aqui exposto permite-nos afirmar que tanto a bibliografia específica sobre o tema quanto o discurso midiático reconhecem que as festas populares, apesar de seu grande potencial de renda, promovem impactos, debilidades e conflitos ambientais, a serem enfrentados pelo poder público, como sugerem Manzini e Vezzoli (2002). Para os autores, é necessário e fundamental o planejamento e organização desses espaços, valorizando os recursos naturais. 
Na avaliação de Prudente (2011), o poder público deve ter, como principal ferramenta de preservação do patrimônio ambiental urbano, a maior aproximação do público com o espaço ou equipamento, seja esse público morador local ou turista. Explica o pesquisador que essa valorização pelo uso, identidade e contemplação evidenciará a relação da comunidade com a cidade, como espaço turístico.

Em relação à preservação ambiental, importa mencionar que, segundo a Política Nacional de Resíduos Sólidos (PNRS), aprovada em 2010, a produção dos resíduos sólidos é de responsabilidade do poder público, das empresas e do próprio cidadão; uma responsabilidade partilhada.

Nessa perspectiva, a participação comunitária é fundamental para o conhecimento do valor do ambiente e do lazer, e para o incentivo a um comportamento destinado à preservação, valorização a revitalização urbana. Dessa forma, o lazer não deve ser entendido

[...] em "si mesmo", mas como uma das esferas de ação humana historicamente situada. A noção de cultura/lazer deve ser entendida em sentido amplo, consistindo "[...] num conjunto de modos de fazer, ser, interagir e representar, definindo o modo pelo qual a vida social se desenvolve. (FARIA, 2001, p. 121).

Por entendermos que a festa popular é uma "indústria de consumo" (simbólico ou não), cabe ressaltar:

[...] o consumo exacerbado traz consigo as mediações que promovem a alienação, o desperdício, o valor de troca expansivo, a completa e descabida realidade em que necessidade e desejo operam em patamares distintos e totalmente antagônicos. (PRUDENTE, 2011, p. 47).

Esse consumo gera um montante de resíduos consideravelmente preocupante, como latas de refrigerante, cervejas, garrafas pet, vidro, pedaços de roupas, vestígios dos carros alegóricos, papéis e outros, sem mencionar o lixo orgânico. Para os lixos recicláveis, a 
solução é a ação da indústria da reciclagem, pois:

[...] A destinação de materiais para a reciclagem desvia, certamente, materiais da rota da coleta e dos aterros. Ela é feita entre os catadores e por firmas especializadas, e em parte pela coleta seletiva. Contudo, deve-se ter presente que esta última é onerosa e não deve estar voltada unicamente para os materiais industrialmente recicláveis. (EIGENHEER, 2003, p. 119).

Estudos mostram que a maioria das cidades brasileiras não praticam o serviço de segregação de resíduos, o que acentua ainda mais a dificuldade de levar avante a tarefa da coleta seletiva. Uma possível solução seria o uso de incineração dos resíduos sólidos, que reduziria o volume dos detritos e a criação de novos aterros (FERREIRA, 1995).

A cidade de Corumbá não possui uma indústria de recicláveis, porém, para continuar a atrair um maior número de turistas, o poder público gera soluções em curto prazo, especialmente no período dos festejos do carnaval, buscando diminuir o impacto dos resíduos.

Pensar e aplicar ações que promovam a sustentabilidade é uma atitude que poderá agregar valor a qualquer produto, sobretudo numa cidade e região cujo maior patrimônio é a própria natureza.

\section{CONSIDERAÇÕES FINAIS}

A festa popular carnaval, como processo material e simbólico, tem trazido à tona o problema da produção de resíduos e impactos ambientais, apontando a interdependência entre o homem e o ambiente e a necessidade de se discutir sustentabilidade.

Como produto cultural e midiático capaz de exportar valores locais e atrair uma economia em direção ao turismo local e ao consumo, o carnaval de Corumbá, MS, poderia traduzir seus resultados em bem-estar aos seus cidadãos e visitantes, porém, nessa articulação direta entre economia e cultura, encontra-se o "arranjo social econômico", movendo a cadeia produtiva do carnaval. 
O carnaval de Corumbá, MS, cuja importância extrapola o regional, tem promovido a economia e a cultura local, porém distante- por parte da população, do comércio local e do poder público - de uma especial atenção para o tratamento dos dejetos produzidos durante os dias de festividade.

Discutir o valor de responsabilidade e equilíbrio do homem e da natureza - para evocar as palavras de Veiga (2006) - induzirá à qualidade de vida e ao bem-estar, diretamente atrelados a melhorias sustentáveis, lugar de origem das políticas públicas que se configuram como instrumentos de mudança.

Nessa perspectiva, órgãos governamentais, sociedade e empresários de Corumbá, MS, unidos em um projeto que reforce os valores da cultura local e a sustentabilidade é o caminho que aponta essa pesquisa. Cabe, pois, investir em gestão de resíduos sólidos e em ações em favor da preservação ambiental, a partir do reconhecimento de que os bens culturais não são mercadorias, e sim um reconhecimento de valores, memórias, crenças e ideologias de uma sociedade.

\section{REFERÊNCIAS}

ADORNO, T. W.; HORKHEIMER, M. Dialética do esclarecimento: fragmentos filosóficos. Rio de Janeiro: Jorge Zahar, 1997.

ARAÚJO, H. Seis milênios de história. Rio de Janeiro: Gryphus, 2003.

BAKHTIN, M. A cultura popular na Idade Média e no Renascimento: o contexto de François Rabelais. São Paulo: Hucitec, 1987.

BARBOSA, L. Sociedade de consumo. Rio de Janeiro: Zahar, 2004.

CANCLINI, N. Culturas híbridas. São Paulo: EDUSP, 2000.

CARNAVAL de Corumbá teve público de 155 mil pessoas. Dourados News, 2005. Disponível em: <http://www.douradosnews.com.br/arquivo/carnavalde-corumba-teve-publico-de-155-mil-pessoas-e822c2f9bc056041dc065aa 0a58cf756>. Acesso em: 5 fev. 2017. 
EIGENHEER, E. M. Lixo, vanitas e morte: considerações de um observador de resíduos. Rio de Janeiro: EDUFF, 2003.

FARIA, I. F. Sustentabilidade e novas territorialidades. Manaus: Editora da Universidade do Amazonas, 2001.

FERREIRA, J. A. Resíduos sólidos: uma discussão ética. Cadernos de Saúde Pública, Rio de Janeiro, v. 11, n. 2, p. 314-320, abr./jun. 1995.

GAUDIN, B. Da mi-carême ao carnabeach: história da(s) micareta(s). Tempo social, São Paulo, v. 12, n. 1, maio 2000.

LEITÃO, S. S. Economia da cultura e desenvolvimento. Z Cultural, ano III, n. 3, 2007. Disponível em: <http://revistazcultural.pacc.ufrj.br/economia-dacultura-e-desenvolvimento-de-sergio-sa-leitao/>. Acesso em: 5 fev. 2017.

LIPOVETSKY, G.; SERROY, J. A cultura-mundo: resposta a uma sociedade desorientada. São Paulo: Companhia das Letras, 2011.

MALECIUVICIUS, P. Esperando recorde, carnaval de Corumbá antecipou até jogo de futebol. Campo Grande News, Lado B, 11/02/2015. Disponível em: <http://www.campograndenews.com.br/lado-b/diversao/esperandorecorde-carnaval-de-corumba-antecipou-ate-jogo-de-futebol>. 2015. Acesso em: 7 fev. 2017.

MANZINI, E.; VEZZOLI, C. O desenvolvimento de produtos sustentáveis. São Paulo: Edusp, 2002.

PRUDENTE, H. A. Bandeiras, comidas e folias. São Paulo: Casa Cultura, 2011. QUEIROZ, M. I. P. O campesinato brasileiro. Petrópolis, RJ: Vozes, 1973.

SOUZA, L. G. O caráter religioso e profano das festas populares. Corumbá, passagem do século XIX para o XX. Revista Brasileira de História, Corumbá, MS, v. 24, n. 48, p. 331-351, 2004.

. História de uma região: Pantanal e Corumbá. São Paulo: Editora Resenha Tributária, 1973.

VEIGA, J. E. Meio ambiente \& desenvolvimento. São Paulo: SENAC, 2006. 
